\title{
Atypical florid vascular proliferation in appendix: a diagnostic dilemma
}

\author{
Mi Jin $\mathrm{Gu}^{1 *}$, Joon Hyuk Choi ${ }^{1}$ and So Hyun Kim²
}

\begin{abstract}
Vascular abnormality of the intestine is rare, except angiodysplasia. We report on an unusual case of atypical florid vascular proliferations of the appendix. A 41 -year old male presented with melena. Adhesioned blood clots in the appendiceal orifice were observed by colonoscopy. He underwent laparoscopic appendectomy. Microscopically, a tiny exophytic polypoid mass was observed. The mass showed pyogenic granuloma-like features in the superficial portion and infiltrative florid vascular proliferations in the deeper portion. Endothelial cells showed minimal nuclear atypia, and mitotic figures were observed infrequently and showed positivity for CD31 and CD34 and negativity for HHV-8. Differential diagnoses include from benign vascular tumor to angiosarcoma or Kaposi's sarcoma, but this lesion does not fit the description of any defined vascular entity. We diagnosed atypical florid vascular proliferations and the patient has been well during the five-month postoperative follow-up.

Virtual Slide: The virtual slide(s) for this article can be found here: http://www.diagnosticpathology.diagnomx.eu/ vs/1386921325843104
\end{abstract}

Keywords: Blood vessel, Proliferation, Atypical, Appendix

\section{Background}

Vascular proliferative lesions occurring in the gastrointestinal tract include tumors and tumor-like lesions of the vessels. With the exception of angiodysplasia, vascular abnormalities of the gastrointestinal tract are uncommon [1]. Seven cases of florid vascular proliferations occurring in the intestinal tract have been reported in English literature [1-3]. All reported cases were associated with intussusception or mucosal prolapse and showed microscopic features that overlap with those of angiosarcoma. Florid vascular proliferations are thought to be a secondary response to repeated mucosal trauma and ischemia and differential diagnosis from angiosarcoma is necessary [1]. We herein report on a challenging case showing unusual microscopic findings of the appendix.

\section{Case report}

A 41-year old male presented with melena. He had no other symptoms, such as migratory pain, right lower quadrant abdominal tenderness with guarding, or leukocytosis.

\footnotetext{
* Correspondence: mjgu@yu.ac.kr

'Department of Pathology, Yeungnam University College of Medicine, 170

Hyeonchung-ro, Nam-gu, Daegu, Rep of Korea

Full list of author information is available at the end of the article
}

Colonoscopy showed non-specific findings, except for adhesioned blood clots in the appendiceal orifice. He underwent laparoscopic appendectomy. No characteristic features were observed on the external surface. Cut sections showed a tiny polypoid mucosa with easy contact bleeding and the appendiceal lumen was filled with blood. Microscopically, inflammatory cells infiltration, diverticulum, parasite, and fecalith were not observed. An exophytic polypoid mass with extensive surface ulceration was observed. The superficial portion of the polyp showed pyogenic granuloma-like features and the deeper portion was composed of vaguely lobulated proliferation of closely packed small capillary-sized vessels and showed infiltrative growth and extension into muscularis propria (Figure 1). Endothelial cells had round to ovoid nuclei and showed minimal nuclear atypia without multi-layering. Mitotic figures were observed infrequently. Endothelial cells stained for CD31 and CD34, but did not stain for human herpes virus type 8 (HHV-8). Immunostaining for SMA, as well as a reticulin stain, fails to demonstrate a convincing well-formed vascular architecture of the type seen in capillary hemangioma; these small vessels are not surrounded by the usual well-developed layer of pericytes and reticulin fibers. Ki-67 labeling index was less than 5\%

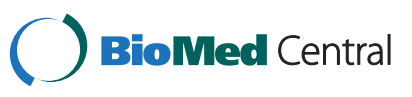





Figure 1 Morphology: (a) The superficial portion showed pyogenic granuloma-like findings on H\&E (original magnification $x$ 100). (b) Endothelial cells maintained vague lobular architectures and exhibited bland cellular morphology on H\&E (original magnification $\times 40$ ). (c) The deeper portion showed infiltrative growth into the muscularis propria on H\&E (original magnification $x$ 40). (d) Endothelial cells showed a positive result for CD34 (original magnification x 100).

and p53 positive endothelial cells were observed rarely. The above mentioned microscopic findings do not fit the description of any defined vascular tumor entity.

\section{Discussion}

In our review of the English literature, vascular tumors or vascular lesions occurring in the appendix have been rarely reported [4-9]. This lesion exhibited infiltrative growth with bland endothelial cell morphology; therefore, we were faced with a dilemma.

Differential diagnoses include from reactive response to preceding appendicitis, reactive vascular lesion, benign to malignant vascular tumor. However, this lesion did not fit the description of any defined benign vascular tumor entity. For reactive response to preceding appendicitis, he had no previous history of appendicitis and there were no microscopic features of acute or chronic appendicitis. The florid benign vascular proliferations occurring in the gastrointestinal tract have been reported and may be confused with angiosarcoma [1-3]. The lesions showed proliferation of small vascular channels extending through the bowel wall, similar to angiosarcoma. However, these lesions maintained lobular architecture and did not feature dissecting, atypical vascular channels with plump and multilayered endothelial cells with nuclear atypia [10]. All of the reported cases of florid vascular proliferations were associated with intussusception and mucosal prolapsed; such clinical findings were not observed in this case. However, in this case, similar microscopic features with florid vascular proliferations were observed. Kaposi's sarcoma, a unique mesenchymal tumor of blood and lymphatic vessels, and is associated with acquired immune deficiency syndrome (AIDS) [9,11-13]. Kaposi's sarcoma may involve any organs and the gastrointestinal tract is the third most affected site. In this case, there was no proliferation of spindle cells with atypical nuclei, producing small slit-like lumina within vascular spaces containing red blood cells, and the patient was a human immunodeficiency virus (HIV)-negative heterosexual man.

Angiosarcomas account for less than $1 \%$ of all soft tissue sarcomas $[10,14]$. Primary gastrointestinal angiosarcoma is exceedingly rare and usually involves stomach and small bowel. Gastrointestinal angiosarcoma usually presents with gastrointestinal bleeding and anemia [10]. Although microscopic findings are differed from those of angiosarcoma, we could not exclude the possibility of a deceptively bland metastasis or primary angiosarcoma which closely mimicks hemangioma. On further work-up, no abnormal lesion was observed in any other organ. The patient has been well during the five-month postoperative follow-up.

In summary, based on the histologic and clinical findings, we think that this was case of atypical florid 
vascular proliferatons, rather than angiosarcoma. Consideration of this lesion may helpful in to prevention of misdiagnosis.

\section{Consent}

Written informed consent was obtained from the patient described in this case report and any accompanying images. A copy of the written consent is available for review by the Editor-in Chief of this journal.

\section{Competing interests}

The authors declare that they have no competing interests.

\section{Authors' contributions}

MJG designed the study, drafted the manuscript and approved of the version to be published. SHK collected clinical data. JHC revised for important intellectual content. All authors read and approved the final manuscript.

\section{Acknowledgements}

We thank Dr. Christopher D M Fletcher in Brigham and Women's hospital in U.S.A. for answer and comments to my consultation.

\section{Author details}

${ }^{1}$ Department of Pathology, Yeungnam University College of Medicine, 170 Hyeonchung-ro, Nam-gu, Daegu, Rep of Korea. ${ }^{2}$ Department of Surgery, Yeungnam University College of Medicine, 170 Hyeonchung-ro, Nam-gu, Daegu, Rep of Korea.

Received: 14 November 2012 Accepted: 19 January 2013

Published: 24 January 2013

\section{References}

1. Bavikatty NR, Goldblum JR, Abdul-Karim FW, Nielsen SL, Greenson JK: Florid vascular proliferation of the colon related to intussusception and mucosal prolapse: potential diagnostic confusion with angiosarcoma. Mod Pathol 2001, 14(11):1114-1118.

2. Ramsden KL, Newman J, Moran A: Florid vascular proliferation in repeated intussusception mimicking primary angiomatous lesion. $J$ Clin Pathol 1993, 46(1):91-92.

3. Adachi S, Hamano R, Shibata K, Yoshida S, Tateishi H, Kobayashi T, Hanada M: Colonic lipoma with florid vascular proliferation and nodule-aggregating appearance related to repeated intussusception. Pathol Int 2005, 55(3):160-164.

4. Baker MS, Wille M, Goldman H, Kim HK: Metastatic kaposi's sarcoma presenting as acute appendicitis. Mil Med 1986, 151(1):45-47.

5. Benevento A, Boni L, Dionigi G, Besana Ciani I, Danese E, Dionigi R: Multiple hemangiomas of the appendix and liver. J Am Coll Surg 2003, 197(5):860-861.

6. Harned RK, Dobry CA, Farley GE: Cavernous hemangioma of the rectum and appendix: report of a case. Dis Colon Rectum 1974, 17(6):759-762.

7. Malygin VN: Cavernous hemangioma of the appendix. Khirurgiia (Mosk) 1990, 12(12):138

8. Meyer-Rochow GY, Lee KM, Smeeton IW, Shaw JH: Primary kaposi's sarcoma of the appendix: a rare cause of appendicitis. ANZ J Surg 2007, 77(5):402-403.

9. Ravalli S, Vincent RA, Beaton H: Primary kaposi's sarcoma of the gastrointestinal tract presenting as acute appendicitis. Am J Gastroenterol 1990, 85(6):772-773.

10. Allison KH, Yoder BJ, Bronner MP, Goldblum JR, Rubin BP: Angiosarcoma involving the gastrointestinal tract: a series of primary and metastatic cases. Am J Surg Pathol 2004, 28(3):298-307.

11. Chetty R, Arendse MP: Gastro-intestinal kaposi's sarcoma, with special reference to the appendix. S Afr J Surg 1999, 37(1):9-11.
12. Girelli CM, Serio G, Rocca E, Rocca F: Refractory ulcerative colitis and iatrogenic colorectal kaposi's sarcoma. Dig Liver Dis 2009, 41(2):170-174.

13. Nagata N, Yazaki H, Oka S: Kaposi's sarcoma presenting as a bulky tumor mass of the colon. Clin Gastroenterol Hepatol 2011, 9(5):A22.

14. Brown CJ, Falck VG, MacLean A: Angiosarcoma of the colon and rectum: report of a case and review of the literature. Dis Colon Rectum 2004, 47(12):2202-2207.

doi:10.1186/1746-1596-8-12

Cite this article as: Gu et al: Atypical florid vascular proliferation in appendix: a diagnostic dilemma. Diagnostic Pathology 2013 8:12.

\section{Submit your next manuscript to BioMed Central and take full advantage of:}

- Convenient online submission

- Thorough peer review

- No space constraints or color figure charges

- Immediate publication on acceptance

- Inclusion in PubMed, CAS, Scopus and Google Scholar

- Research which is freely available for redistribution 